\title{
EMPA and its activities in the field of building materials, elements and structures
}

\author{
F. EGGIMAN, President; U. MEIER, Director; \\ H. W. FRITZ, Head of Division Building Materials \\ The Swiss Federal Laboratories for Materials Testing and Research (EMPA), CH-8600 Dübendorf, Switzerland
}

EMPA is an an interdisciplinary organization providing, as the name implies, both research facilities and routine testing to suit a range of industrial, environmental and official governmental requirements. Some specific practice-oriented current research projects are described which exemplify many of EMPA's capabilities.

EMPA was founded in 1880 as the "Materiais Testing Institute of the Swiss Federal Institute of Technology' under the leadership of Prof. L. v. Tetmajer. It was already recognized then that the study of the properties of materials and their evaluation by a neutral body were indispensable. This basic goal has remained valid for EMPA up to the present. However, in the meantime, its fields of activity have expanded considerably. EMPA has always adjusted its role not only in society, industry and science, but also according to the rapid development of engineering and technology and to ecological problems and advances for European integration. Some of the recent fields of interest include:

applied physics in building, energy conservation, environmental protection, testing of finished elements or entire structures;

technical consumer information, evaluation of complete systems and safety requirements.

The strategy chosen in 1988 by the Swiss Federal Laboratories for Materials Testing and Research now shows that EMPA had recognized the changing times. Research, development and consulting services have become important activities in addition to our traditional testing work. Thus, research, development and consulting services are favoured more than routine testing, which offers less synergy.

From a handful of employees in 1880, EMPA has grown into an establishment of approximately 700 people, 520 of whom work in Dübendorf, some 30 in Thun and 150 in St. Gallen. The aerial view in Fig. 1 shows the premises of EMPA Dübendorf, and Fig. 2 shows its largest testing hall, where the structure section can test large elements. EMPA strongly emphasizes collaboration amongst the different disciplines. Furthermore, EMPA has dedicated itself to promoting safety for man and environment, and supports projects that strengthen the national economy. As a connecting link between science and economy or between fundamental scientific knowledge and technical application, EMPA concentrates on practice-oriented research and development.

Activities at EMPA concerning building materials cover a wide range, e.g.

practice-oriented research and development materials testing with synergy to consulting services transfer of knowledge by publishing research results as well as by teaching activity (lectures and seminars at technical colleges and universities)

active collaboration in establishing standards and regulations as well as enforcement of Swiss Federal decrees.

EMPA is a neutral and objective organization operating according to commercial principles. Though much of its work is done for public benefit, almost $50 \%$ of its total expenses are covered by earnings accruing from external testing services.

The eight contributions that follow give a good overview of specific practice-oriented research projects being carried out at EMPA in the field of building, structures, materials, testing and measurement techniques:

Investigation of the dynamic behaviour of civil engineering structures - new developments

R. CANTIENI 


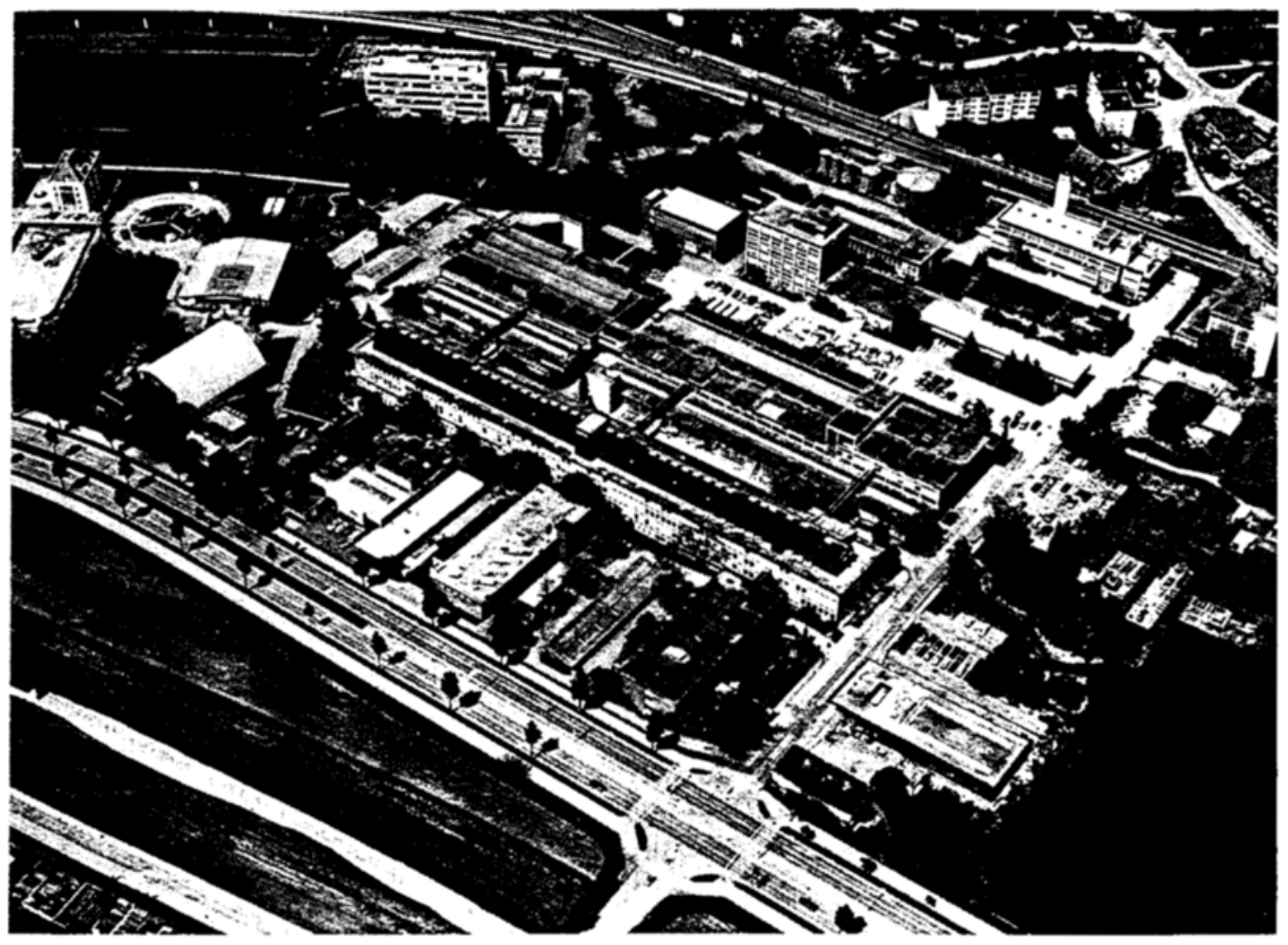

Fig. 1 Aerial view of EMPA Dübendorf.

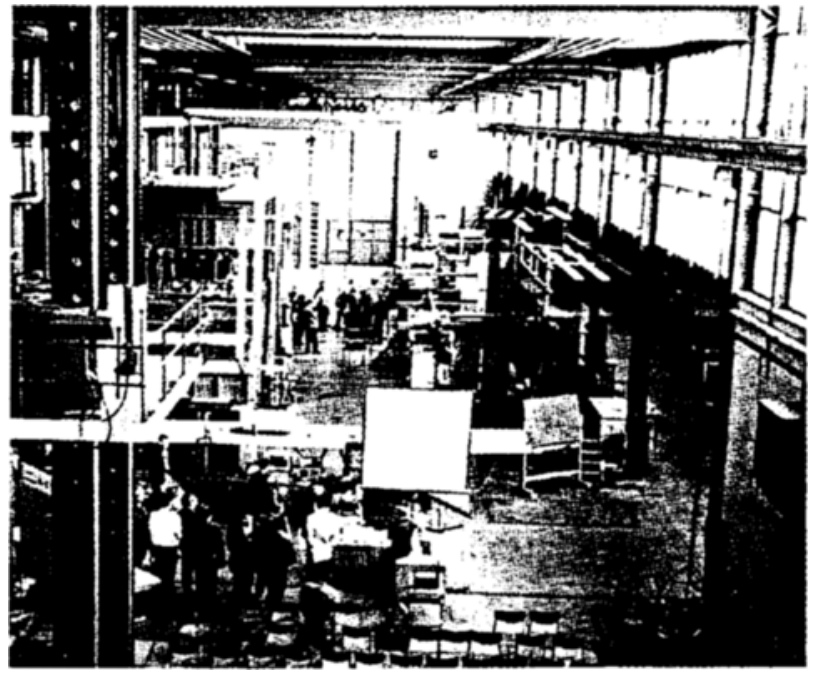

Fig. 2 The largest testing hall at EMPA Dübendorf (Photo: 'Schweizer Baublatt').

Rehabilitation and retrofitting of existing structures through external bonding of thin carbon fiber sheets U. MEIER
Fibre reinforced plastic splices for joints in timber structures

A. U. MEIERHOFER

Arrest of rapid crack propagation in polymer pipes P. FLÜELER, M. FARSHAD

Fibre optic sensors for civil structures monitoring U. SenNhauser, R. BrönnimanN, PH. M. Nellen

Quality change and structural damage of polymerbitumen binders during road construction

M. N. Partl, M. Hugener, Ch. RaAB

Characterization of emissions of volatile organic compounds from building materials

R. GEHRIG

One-dimensional water transport in covercrete application of non-destructive methods

J. KaufmanN, W. Studer 